\title{
Psychiatric Problems in Pulmonary Tuberculosis: Depression and Anxiety
}

\author{
Jacqueline V. Lara-Espinosa*, Rogelio Hernández-Pando
}

Departamento de Patología, Laboratorio de Patología Experimental, Instituto Nacional de Ciencias Médicas y Nutrición "Salvador Zubirán”, Avenida Vasco de Quiroga 15, Colonia Belisario Domínguez Sección XVI, Delegación Tlalpan, Ciudad de México, México

Email: ‘jvle_29031991@comunidad.unam.mx, rhdezpando@hotmail.com

How to cite this paper: Lara-Espinosa, J.V and Hernández-Pando, R. (2021) Psychiatric Problems in Pulmonary Tuberculosis: Depression and Anxiety. Journal of Tuberculosis Research, 9, 31-50. https://doi.org/10.4236/jtr.2021.91003

Received: December 19, 2020

Accepted: March 28, 2021

Published: March 31, 2021

Copyright $\odot 2021$ by author(s) and Scientific Research Publishing Inc. This work is licensed under the Creative Commons Attribution International License (CC BY 4.0). http://creativecommons.org/licenses/by/4.0/

\begin{abstract}
Depression, anxiety and tuberculosis are common conditions with significant public health implications. The connection among these conditions is syndemic: the incidence of one increases the chance of developing the other, with clusters of biological, social and psychological interaction. Therefore, it has become crucial to understand better the mechanisms liable for the physiological process related to these three conditions. The present review focuses specifically on shared social events (perception of illness severity, social stigma, poverty and social isolation) and biological pathways (central response of the immune system within the CNS, the activation of the HPA axis and the SNS) that may mechanistically elucidate the depression-anxiety-tuberculosis association and discuss interventions prospects and significant issues to be arranged by future clinical and research implications.
\end{abstract}

\section{Keywords}

Tuberculosis, Anxiety, Depression

\section{Introduction}

Tuberculosis (TB), the oldest human pandemic, remains the leading cause of death among infectious diseases, regardless of the worldwide use of a live attenuated vaccine and several other efficient antibiotics [1]. The disease is caused by infection via the lung with Mycobacterium tuberculosis (Mtb), identified as a pathogen by Robert Koch in 1882. TB is predominantly a lung disease, with pulmonary TB responsible for $70 \%$ of cases, although $\mathrm{Mtb}$ can spread to other organs, including lymph nodes, bone, and meninges, causing extrapulmonary disease [2]. 
In 2019, 10.0 million people suffered TB, and 1.2 million people died due to this disease [3]. Moreover, one-quarter of the global human population is latently infected, providing a large reservoir for upcoming cases of active TB [4], mostly in the underdeveloped world due to poverty, absence of healthy living environments and adequate medical care [1]. Another problem related to poverty is the prevalence of common mental disorders (CMD), including depression, anxiety and somatoform disorders [5]. In recent years, mental disorders' burden continues to grow with significant impacts on health and principal social, human rights and economic consequences in all countries associated with increased functional disability and mortality [6].

Depression is a mental disorder that manifests with depressed mood, loss of interest or pleasure, decreased energy, state of mind of guilt or low self-worth, disturbed sleep or appetite, and lousy concentration [7]. Depression accounts for $4.4 \%$ of total disability-adjusted life-years worldwide and is estimated to affect 350 million people and 1.0 million commit suicide each year [8]. Furthermore, depression frequently associates with anxiety symptoms [7], and the incidence of depression is high amongst people with chronic disease [9].

Anxiety is a vague, subjective, non-specific feeling of uneasiness, apprehension, tension, (excessive nervousness) fears, and a sense of impending doom, irrational avoidance of objects or situation and anxiety attack [6]. Moreover, anxiety is associated with decreased functioning and quality of life, and can occur in the context of medical illness, which is one of the most frequent reactions that accompany the onset or recurrence of respiratory illness [10]. However, most of those with mental health problems are not diagnosed or treated ineffectively in low and middle-income countries [11].

Both CMD and TB are global public health problems that have a considerable impact on human health. Moreover, TB and CMD share common risk factors including poverty, drugs addiction and homelessness. Nevertheless, the disease's microbiological resolution spends much of the attention within TB control [12], and its relationship with CMD is either unappreciated or hardly ever considered. However, in recent years the number of epidemiological studies about the association between CMD and TB has been increased. Lung diseases are among the chronic medical conditions that are strongly related to psychiatric disorders [13]. Evidence shows that anxiety, depression and emotional distress are significant dimensions on the matter and incapacity of TB and they are strictly related to the severity of symptoms, the quantity of reported symptoms, higher rates of health services use, low treatment compliance, more extensive course of treatment, reduced control of the disease and death (Figure 1) [14].

The current review compiles the epidemiological information connecting TB and depression and anxiety. Additionally, we present biological mechanisms that would explain the TB-depression-anxiety association. We conclude by discussing interventional prospects and significant issues to be arranged by future clinical and research implications. 


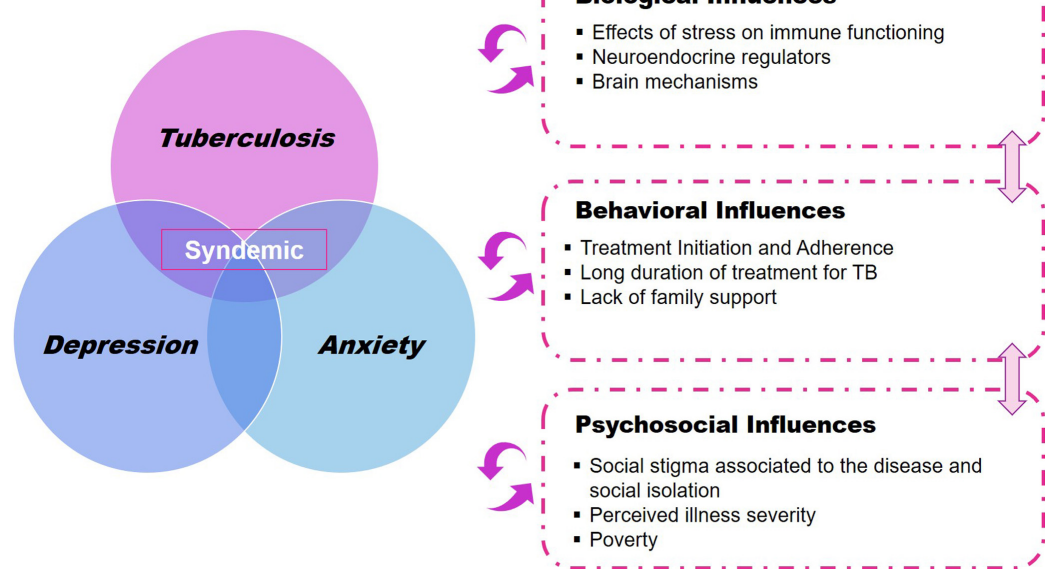

Figure 1. Tuberculosis, depression and anxiety syndemic is a significant global public health problem. The prevalence of depression and anxiety increases the outcome of TB and vice versa. Psychosocial, behavioural and biological factors participate in the development of these three diseases. The perception of illness severity, social stigma, social isolation, and poverty in TB patients generates a lack of family support, decreasing treatment initiation and adherence; thus, TB treatment is longer. Simultaneously, the infection with Mtb generates the activation of myriad biological factors that participate in the development of depression and anxiety that increase the prevalence of the psychosocial and behavioural problems.

\section{Epidemiological Information for a Bidirectional Link between Anxiety, Depression and TB}

Epidemiological evidence supports an association between depression, anxiety and TB. In the current review, we made a systematic analysis of research focused on the relationship of TB with anxiety and depression from 1981 to 2020. Different surveys have been used to evaluate depression and anxiety in patients with TB (such as Beck's depression inventory, Hospital Anxiety and Depression Scale, among others), these surveys use factors that make it possible to distinguish between the common symptoms of tuberculosis infection and those developed in these psychiatric illnesses. Interesting, in high income and low and middle-income countries there is an important relationship between $\mathrm{TB}$, anxiety and depression, and countries with a high prevalence of TB like India, Pakistan and China have reported a strong association of the disease with the mentioned mental disorders (Figure 2). Although most of the studies do not provide specific information or biological mechanisms which could explain the link between $\mathrm{TB}$ and $\mathrm{CMD}$, it is crucial to notice that the prevalence of depression among TB patients ranges between $1.71 \%$ to $87.5 \%$ [15] [16] and anxiety between $7.14 \%$ to $74 \%$ [17] [18]. The difference might be due to the unlikeness in study design, data collection tool, sample size and the difference in participants and country population. These findings demonstrate that TB and CMD's link is more robust than between CMD and other diseases, such as obesity or cancer, ranging from $25 \%$ to $33 \%$ [8]. Patients with more prolonged illness duration have a higher incidence of depression and anxiety [19], and depression is higher in patients with 


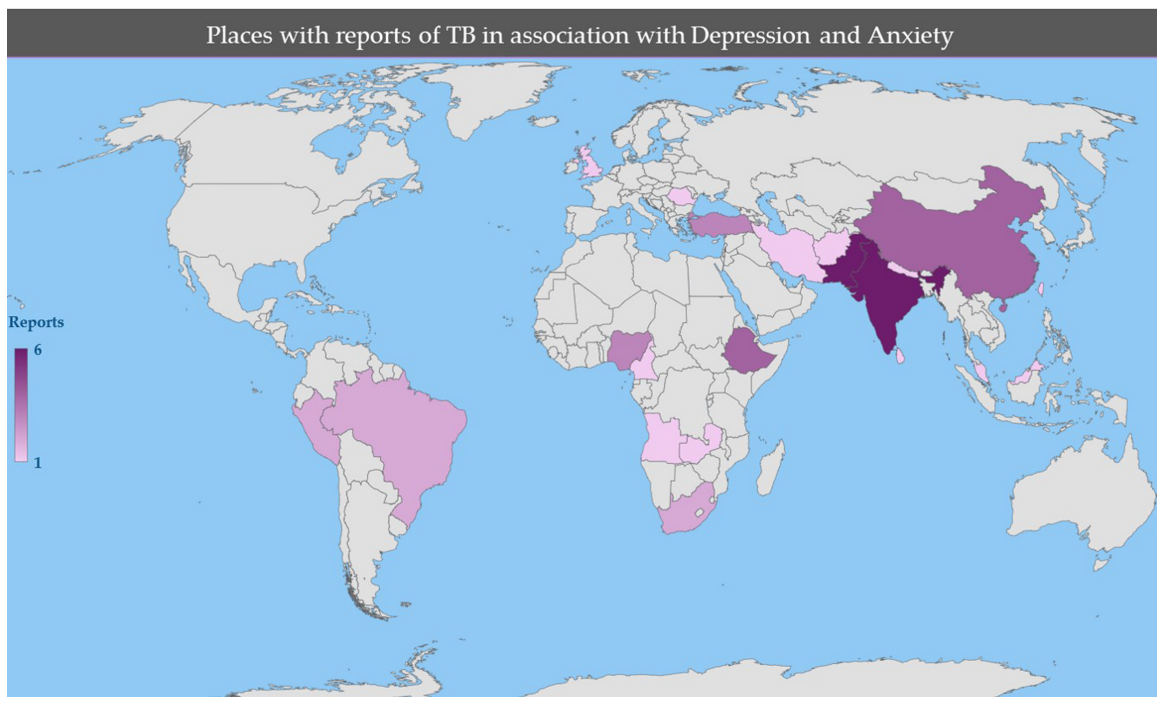

Figure 2. Epidemiological evidence supports an association between depression, anxiety and TB in high income and low and middle-income countries. Countries with a high prevalence of TB like India, Pakistan and China have reported an association of the disease with depression and anxiety. This figure was made with the data obtained from a systematic review of research focused on the relationship of TB with anxiety and depression from 1981 to 2020 in PubMed and Google Academic (Table 1).

pulmonary than extrapulmonary TB [18]. An important aspect is that even under treatment, TB patients still suffer depression and anxiety scores remained high [20] [21], being adult patients more prone to depression [22]. Moreover, multidrug-resistant TB (MDR-TB) patients present higher levels of depression [16] [23] [24] [25]. Besides, TB patients present low to moderate rates of suicidal ideation (9.0\%) and a history of suicide attempt (3.1\%) [15]. Table 1 summarises previous reports of epidemiological information about depression and/or anxiety among TB patients.

\section{Social Events Linking Depression, Anxiety and TB}

Most research in patients with TB and its relationship with depression and anxiety has focused on the prevalence of these psychiatric diseases in patients with TB and its epidemiological importance. The causes of these diseases have been related in most cases to social factors such as social stigma, perception of illness severity, poverty and social isolation. Risk factors, including medical co-morbidities, drug abuse, alcohol dependence, and low educational attainment levels are significant predictors of depression in patients with TB (Figure 3) [28]. This section of the review will present social factors related to depression and anxiety in TB patients.

\subsection{Perception of Illness Severity}

Most of the patients considered TB as an infectious and deadly disease that could be cured with great difficulty and a high relapse rate. They perceived TB as a disease that caused social stigmatisation and tended to deny the diagnosis and 
Table 1. Overview of research examining the association between depression, anxiety and Tuberculosis.

\begin{tabular}{|c|c|c|c|c|c|}
\hline Place & Cite & Sample & Scale & Depression & Anxiety \\
\hline India & $\begin{array}{l}\text { Mathai et al., } \\
1981 \text { [17] }\end{array}$ & $\begin{array}{c}70 \text { and } 70 \\
\mathrm{HC}\end{array}$ & ICD-9 & $15.71 \%$ & $7.14 \%$ \\
\hline Nigeria & $\begin{array}{l}\text { Aghanwa \& } \\
\text { Erhabor, } 1998 \text { [23] }\end{array}$ & 53 & ICD-10/GHQ-30 & $30.2 \%$ & \\
\hline Turkey & $\begin{array}{l}\text { Aydin \& Uluşahin, } \\
2001[26]\end{array}$ & 119 & $\begin{array}{l}\text { CIDI, ICD-10, DSM-IV } \\
\text { and GHQ-12 }\end{array}$ & $21 \%$ & $20.3 \%$ \\
\hline Peru & $\begin{array}{l}\text { Vega et al., } 2004 \\
{[24]}\end{array}$ & 75 & DSM-IV & $52.2 \%$ & $8.7 \%$ \\
\hline Pakistan & $\begin{array}{l}\text { Husain et al., } 2008 \\
{[8]}\end{array}$ & 108 & HAD & $46.3 \%$ & $47.2 \%$ \\
\hline Nigeria & Issa et al., 2009 [27] & 65 & PHQ-9 & $27.7 \%$ & \\
\hline England & $\begin{array}{l}\text { Kruijshaar et al., } \\
2010[20]\end{array}$ & 61 & SF-36/EQ-5D & $48 \%$ & $22 \%$ \\
\hline Pakistan & $\begin{array}{l}\text { Aamir \& Aisha, } \\
2010[28]\end{array}$ & 65 & HAD & $72.2 \%$ & $72.2 \%$ \\
\hline Pakistan & $\begin{array}{l}\text { Sulehri et al., } 2010 \\
{[29]}\end{array}$ & 60 & BDI-II & $80 \%$ & \\
\hline Nigeria & $\begin{array}{l}\text { Ige \& Lasebikan, } \\
2011[30]\end{array}$ & 88 & HAD & $45.5 \%$ & \\
\hline Romania & $\begin{array}{l}\text { Adina et al., } 2011 \\
\text { [31] }\end{array}$ & 60 & BDI/STAI & $78 \%$ & $42 \%$ \\
\hline South Africa & $\begin{array}{l}\text { Peltzer et al., } 2013 \\
\text { [32] }\end{array}$ & 4900 & Kessler-10 & $81.1 \%$ & $32.9 \%$ \\
\hline Peru & $\begin{array}{l}\text { Ugarte-Gil et al., } \\
2013 \text { [33] }\end{array}$ & 325 & CES-D & $37 \%$ & \\
\hline Zambia & $\begin{array}{l}\text { Van den Heuvel et } \\
\text { al., } 2013 \text { [14] }\end{array}$ & 231 & DSM-IV/ICD-10 & $9.3 \%$ & $27.9 \%$ \\
\hline Pakistan & $\begin{array}{l}\text { Rubeen et al., } 2014 \\
\text { [21] }\end{array}$ & $\begin{array}{c}70 \text { and } 70 \\
\mathrm{HC}\end{array}$ & $\mathrm{HAD}$ & $37.1 \%$ & $37.1 \%$ \\
\hline Malaysia & Atif et al., 2014 [34] & 336 & SF-36 & $67.1 \%$ & \\
\hline $\begin{array}{c}\text { The } \\
\text { Philippines }\end{array}$ & $\begin{array}{l}\text { Masumoto et al., } \\
2014 \text { [35] }\end{array}$ & 561 & PHQ-9 & $16.8 \%$ & \\
\hline Turkey & $\begin{array}{l}\text { Kibrisli et al., } 2015 \\
\text { [36] }\end{array}$ & $\begin{array}{c}94 \text { and } 99 \\
\text { HC }\end{array}$ & LSAS & & $68.4 \%$ \\
\hline India & $\begin{array}{l}\text { Singh et al., } 2015 \\
\text { [19] }\end{array}$ & $\begin{array}{l}100 \text { and } \\
100 \mathrm{HC}\end{array}$ & ICD-10/TMAS/BDI & $44 \%$ & $38 \%$ \\
\hline Ethiopia & $\begin{array}{l}\text { Duko et al., } 2015 \\
\text { [37] }\end{array}$ & 424 & $\mathrm{HAD}$ & $43.4 \%$ & $41.5 \%$ \\
\hline Iran & $\begin{array}{l}\text { Emami et al., } 2015 \\
{[38]}\end{array}$ & 146 & SCL-90 & $52.7 \%$ & $41.1 \%$ \\
\hline Taiwan & Yen et al., 2015 [15] & 4629 & ICD-9-CM & $1.71 \%$ & \\
\hline
\end{tabular}




\section{Continued}

\begin{tabular}{|c|c|c|c|c|c|}
\hline India & $\begin{array}{l}\text { Kumar et al., } 2016 \\
{[22]}\end{array}$ & 100 & GHQ-12/BDI-II/HARS & $47.29 \%$ & $52.71 \%$ \\
\hline Sri Lanka & $\begin{array}{l}\text { Galhenage et al., } \\
2016 \text { [39] }\end{array}$ & 430 & HAD & $25.2 \%$ & $14.7 \%$ \\
\hline China & $\begin{array}{l}\text { Chen et al., } 2016 \\
{[40]}\end{array}$ & 1105 & SDS/SAS & $29.8 \%$ & $13.5 \%$ \\
\hline Turkey & $\begin{array}{l}\text { Yilmaz et al., } 2016 \\
\text { [41] }\end{array}$ & 208 & HAD & $60.5 \%$ & $26 \%$ \\
\hline Pakistan & $\begin{array}{l}\text { Amreen \& Rizvi, } \\
2016[42]\end{array}$ & 100 & PHQ-9/GAD-7 & $56 \%$ & $65 \%$ \\
\hline Cameroon & $\begin{array}{l}\text { Kehbila et al., } 2016 \\
\text { [43] }\end{array}$ & 265 & PHQ-9 & $61.1 \%$ & \\
\hline Angola & $\begin{array}{l}\text { Paulo \& Peixoto, } \\
2016[44]\end{array}$ & 81 & HAD & $49.4 \%$ & $38.3 \%$ \\
\hline Brazil & $\begin{array}{l}\text { Dos Santos et al., } \\
2017 \text { [45] }\end{array}$ & 86 & HAD & $31.4 \%$ & $38.4 \%$ \\
\hline Afghanistan & $\begin{array}{l}\text { Javaid et al., } 2017 \\
\text { [16] }\end{array}$ & 289 & DSM-IV/HAM-D & $87.5 \%$ & \\
\hline India & $\begin{array}{l}\text { Shyamala et al., } \\
2018 \text { [18] }\end{array}$ & 262 & PHQ-9 & $80.37 \%$ & $74 \%$ \\
\hline China & $\begin{array}{l}\text { Wang et al., } 2018 \\
\text { [11] }\end{array}$ & 1252 & HAD/PHQ-9 & $18.13 \%$ & $18.37 \%$ \\
\hline China & $\begin{array}{l}\text { Gong et al., } 2018 \\
\text { [46] } \\
\text { Qiu et al., } 2018 \text { [47] }\end{array}$ & 1342 & CES-D & $48 \%$ & \\
\hline Pakistan & $\begin{array}{l}\text { Walker et al., } 2018 \\
{[48]}\end{array}$ & 1279 & PHQ-9 & $42.8 \%$ & $74 \%$ \\
\hline India & $\begin{array}{l}\text { Salodia et al., } 2019 \\
\text { [49] }\end{array}$ & 106 & PHQ-9 & $23.6 \%$ & \\
\hline Brazil & $\begin{array}{l}\text { De Castro-Silva et } \\
\text { al., } 2019 \text { [50] }\end{array}$ & 260 & PHQ-9 & $60.2 \%$ & \\
\hline Ethiopia & $\begin{array}{l}\text { Dasa et al., } 2019 \\
\text { [51] }\end{array}$ & 403 & PHQ-9 & $51.9 \%$ & \\
\hline Nepal & $\begin{array}{l}\text { Walker et al., } \\
2019 \text { [25] }\end{array}$ & 135 & HSCL-25 & $22.2 \%$ & $15.6 \%$ \\
\hline Ethiopia & $\begin{array}{l}\text { Ambaw et al., } \\
2020 \text { [52] }\end{array}$ & 648 & PHQ-9 & $73.6 \%$ & \\
\hline Ethiopia & $\begin{array}{l}\text { Mohammedhussein } \\
\text { et al., } 2020 \text { [53] }\end{array}$ & 410 & HAD & $55.9 \%$ & $54.6 \%$ \\
\hline
\end{tabular}

This table was made with information from research between 1981 and 2020. There are blank spaces when the cited article just reported the data or either depression or anxiety. Healthy Controls (HC). 30-item General Health Questionnaire (GHQ-30). Beck Depression Inventory-II (BDI-II). Beck's depression inventory (BDI). Center for Epidemiological Studies Depression Scale (CES-D). Composite international diagnostic interview (CIDI). Diagnostic and Statistical Manual of Mental Disorders (DSM-IV). European Quality of Life-5 Dimensions (EQ-5D). General Health Questionnaire-12 (GHQ-12). Generalised Anxiety Disorder Questionnaire (GAD-7). Hamilton Anxiety Rating Scale (HARS). Hamilton Depression Rating Scale (HAM-D). Hopkins Symptom Checklist (HSCL-25). Hopkins Symptom Checklist-25 (HSCL-25). Hospital Anxiety and Depression Scale (HAD). International Classification of Disease, tenth edition (ICD-10). International Classification of Diseases, Ninth Edition, Clinical Modification (ICD-9-CM). Kessler Psychological Distress Scale (Kessler-10). Liebowitz Social Anxiety Scale (LSAS). Riker Sedation-Agitation Scale (SAS). Sheehan Disability Scale (SDS). Short Form 36 Health Survey (SF-36). State-Trait Anxiety Inventory (STAI). Symptom Checklist-90 (SCL-90). Taylor's Manifest Anxiety Scale (TMAS). The Patient Health Questionnaire (PHQ-9). 


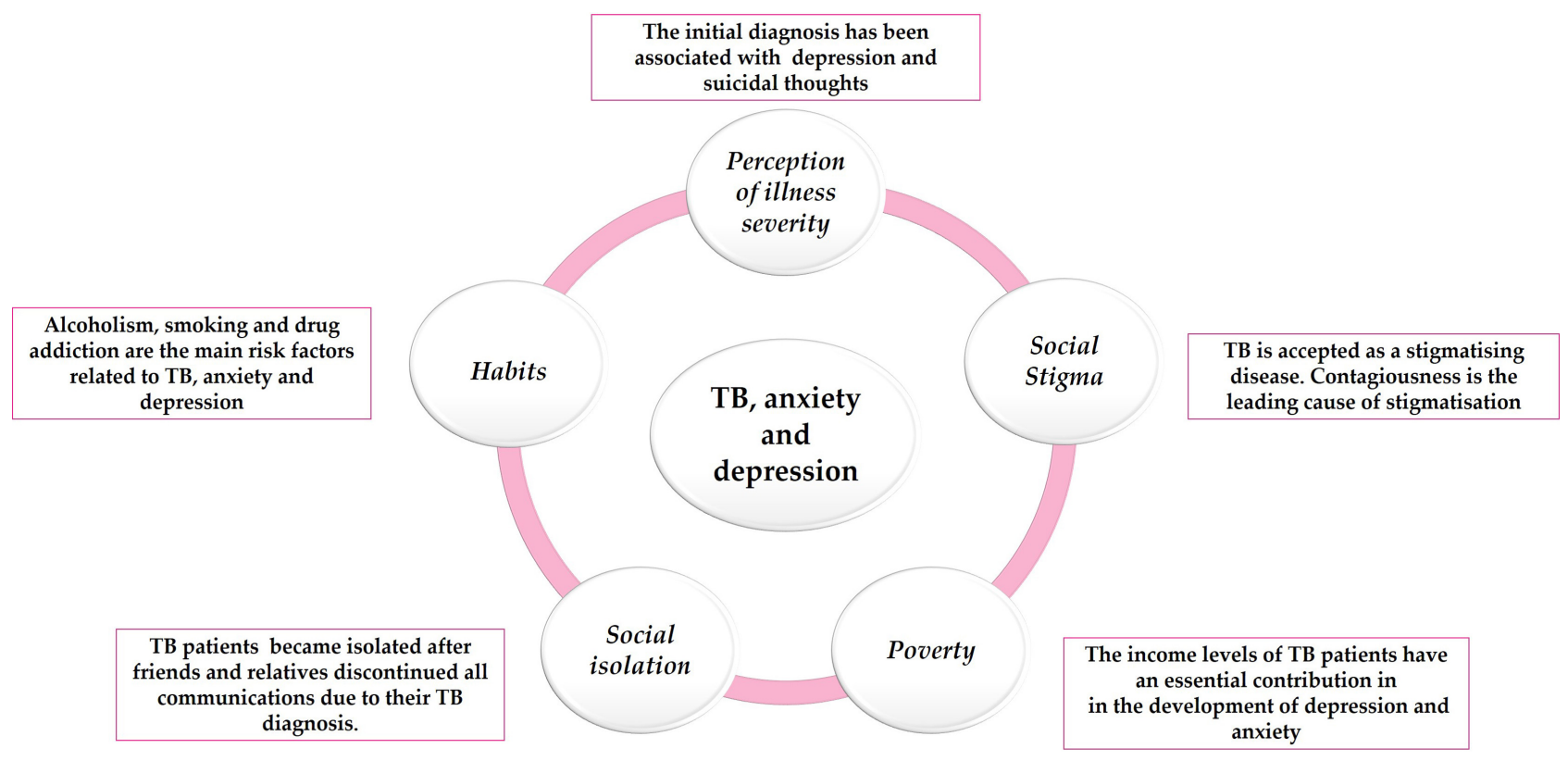

Figure 3. Social events are linking depression, anxiety and TB. Perception of illness severity. Social Stigma. Poverty. Social isolation. Alcoholism, smoking and drug addiction are the principal related social aspects.

conceal the treatment. Moreover, TB patients are perceived as infectious by others within the community, which has various social consequences, such as stigmatisation, social isolation, and rejection of the patient and family members [54]. These social consequences made patients delay seeking help, deny the diagnosis, and reject the treatment, contributing to TB transmission and prevalence [55]. Concerning mental diseases, it has been noticed that TB patients react to the disclosure of the diagnosis with worry (50\%) and suicidal thoughts (9\%), and the initial diagnosis has been associated with subsyndromal depression [15] [32].

\subsection{Social Stigma}

TB is known to be a social illness condition that involves profound emotional experiences, alienation from family members and isolation. Besides, TB is accepted as a stigmatising disease, as well [41]. Stigmatisation is a social element of health and a vital factor which impedes the treatment of the many mental illnesses. Some studies have shown that similarly, it affects TB treatment, mostly in developing countries [56]. TB carries a social stigma due to the infection's perceived consequences, based mostly on set cultural and social understandings of the disease [57]. Most authors identify the perceived contagiousness of TB as a leading cause of stigmatisation. Other factors that contribute to stigmatisation are the lack of knowledge regarding routes of TB transmission, malnutrition, poverty, being foreign-born, low social class, homelessness, drug addiction, to affected individual's community, believes that the patient must have done something wrong to deserve to be infected [57] [58]. Stigma and discrimination cause low uptake of health services, delayed diagnosis and inadequate treatment 
compliance; there is an increased risk of drug resistance. Furthermore, TB stigma has an observable association with stigmatised groups' mental health [59]. TB patients report facing social stigma and isolation from family and friends and suffering from depression and anxiety due to their disease [60]. Thus, social stigma may be related to depression and anxiety in TB patients.

\subsection{Poverty}

TB is an infectious disease with both medical and social dimensions, characterised by its close relation to poor socio-economic conditions as TB infection can substantially impact economic opportunities [41]. It is the socio-economic development and poverty that drive TB rates globally. When the patients' income levels are considered, $20 \%$ of the patients with high-income present psychiatric morbidity, which contrasted with $39 \%$ of patients with low socio-economic income [53]. Thus, the income levels of TB patients have an essential role in the presence of depression and anxiety.

\subsection{Social Isolation}

The most common outcome of TB stigma is isolation from other members of the community [54]. Negative responses from others who learn of a TB diagnosis can increase the physical effect of TB and the social impact of necessary isolation for TB patients [41]. TB patients became isolated after friends and relatives discontinued all communications after their TB diagnosis. Moreover, even after patients were determined to be "non-infectious" by public health care workers, their family and friends often viewed them as "unsafe" and avoided interacting with them. Almost all TB patients experienced some level of abandonment by friends or family, mostly due to fear and limited understanding of TB transmission [61] [62]. Thus, social isolation and rejection could contribute to depression and anxiety.

\section{Biological Mechanisms Connecting Depression, Anxiety and TB}

As we have mentioned, most of the research about the relationship of TB with depression and anxiety focus on the epidemiological aspect and the social causes of this association. However, research carried out in the past two decades has identified the role of the immune system's activation as a potential biological mechanism in psychopathology development [63]. Another biological mechanism related to depression and anxiety is the activation of diverse neuroendocrine regulators (Figure 4). In this section, these mechanisms and their relationship with TB will be described.

\subsection{Immuno-Inflammatory Activation}

Inflammatory response plays an important role in the pathogenesis of both infectious and non-infectious diseases. Depression is frequently an co-morbidity 


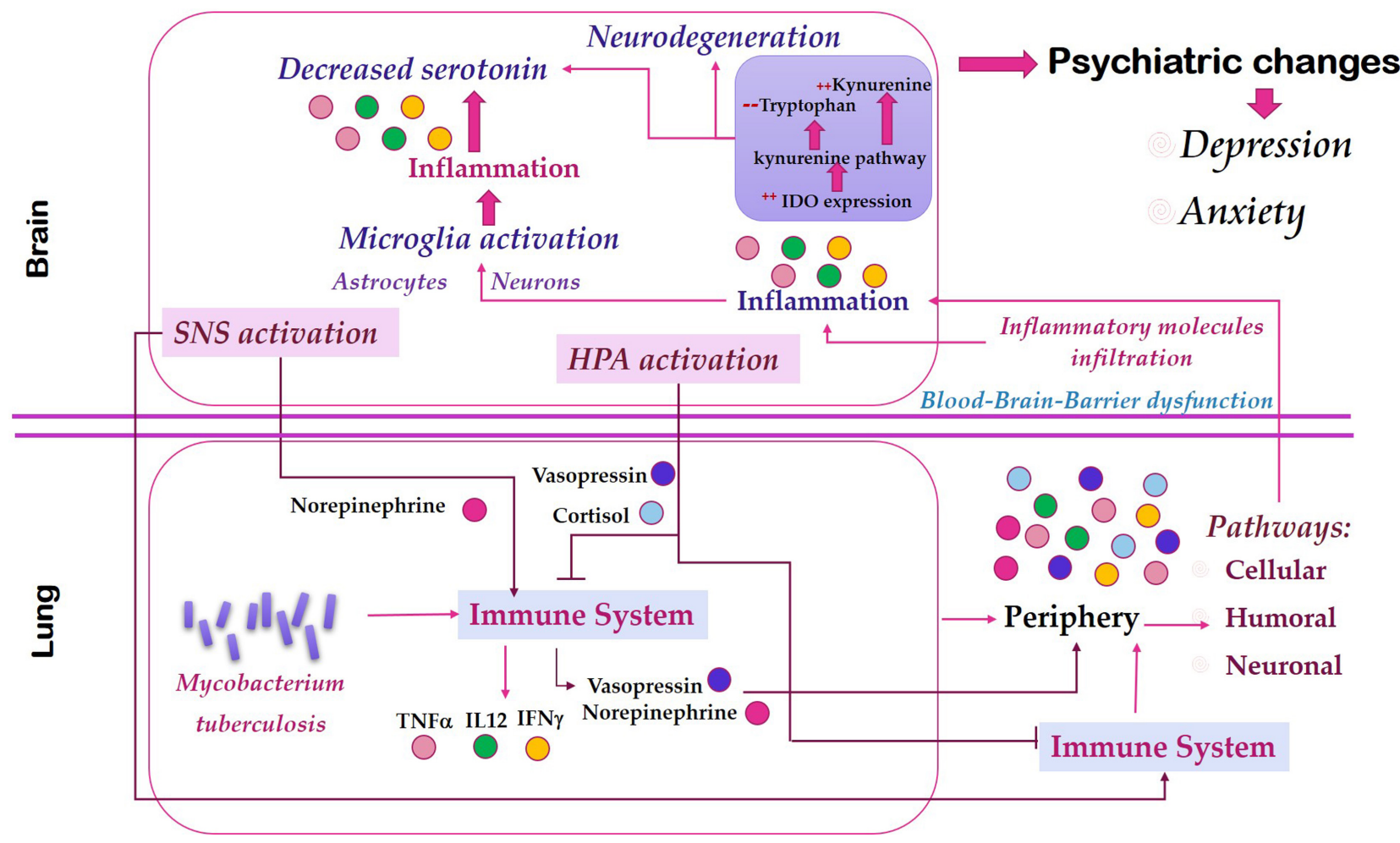

Figure 4. The biological mechanisms that could be related to depression and anxiety during pulmonary TB are represented in this illustration. The infection with Mtb results in the induction of several cytokines which generates chronic inflammation. Systemic inflammation alters the immune system's central response within the CNS, the activation of the HPA axis and the SNS. All these changes could be contributing to the onset of psychiatric problems in TB patients.

with both infectious and non-infectious diseases [64]. Active TB starts as a pulmonary exudative inflammatory process. Th1 lymphocytes mediate the protective adaptive immune response against TB with high production of IFN- $\gamma$ and CD8+ T cytotoxic cells in animals and humans [65]. Mtb infection results in the induction of several cytokines, some of them playing an essential role in resistance, such as type 1 cytokines [66].

During the inflammatory process, cytokines can reach and overproduce in the brain by three different pathways: the neural, the cellular and the humoral pathways. In the neural pathway, immune stimuli activate pulmonary vagal afferents through cytokines released by cells involved in the immune response, or PAMS that can bind to receptors for cytokines and TLRs that exist in the end terminals of the vagus nerve. In the humoral pathway circulating $\operatorname{IL} 1 \beta \operatorname{TNF} \alpha$, and IL- 6 can cross the blood-brain barrier and reach the cerebrospinal fluid, the fluid in the brain's interstitial spaces, and the spinal cord through a saturable transporter-dependent mechanism that works at high cytokines plasma concentrations. Finally, in the cellular pathway, cells of the immune response can infiltrate the brain parenchyma through places that lack the blood-brain barrier [65]. Proinflammatory cytokines such as IFN $\gamma$ and TNF $\alpha$ might affect the development of depressive disorder by regulating neuronal excitability, synaptic transmission, synaptic plasticity, and neuronal survival. These mechanisms generate 
brain inflammation, which induces depression by diverse pathophysiological processes, such as disturbing of monoaminergic neurotransmission, oxidative injury, and hippocampal neuronal damage [63]. Thus, peripheral inflammation generated in the lung by Mtb infection could be participating in the establishment of central nervous system inflammation and the development of neuropsychiatric diseases such as depression and anxiety in patients with TB. We have recently shown neuroinflammation, and these neuropsychiatric abnormalities in an experimental model of progressive pulmonary TB without brain infection [67].

\subsection{Neuroendocrine Regulators}

TB is characterised by chronic granulomatous inflammation of the lung that produces systemic immune-neuroendocrine responses that have been associated with its pathophysiology and disease outcome. TB affects nervous centres and many endocrine glands, including the hippocampus, hypothalamus, pituitary, thyroid and adrenals. The bidirectional interactions between the endocrine and immune systems are well known. Proinflammatory cytokines released during the immune response against Mtb mediate abnormal production of several hormones and modify the Central Nervous System (CNS) response by activating the hypothalamic-pituitary-adrenal (HPA) axis [68], the sympathetic nervous system (SNS) [69] [70] and the vasopressinergic system [71]. These changes impair neuroendocrine activity, neurotransmitter function, neurocircuitry, and the immune response against Mtb.

\subsubsection{The Hypothalamic-Pituitary-Adrenal (HPA) Axis}

The ability to rapidly and adaptively respond to environmental threats and stressors is critical to survival. Interactive physiological responses involving the HPA axis and the autonomous nervous systems influence metabolic, immune, and cardiovascular parameters to respond and adapt appropriately to environmental stressor factors [72]. One such mediator is the glucocorticoid (GC) cortisol, which is the end product of the HPA axis. Cortisol serves various crucial roles in promoting allostasis, mediating and suppressing healthy stress responses [73]. Nevertheless, chronic exposure to GCs leads to changes in the brain regions responsible for regulating the stress response (e.g. the hippocampus) and may contribute to the pathophysiology of anxiety and mood disorders [74].

Hypersecretion of ACTH and glucocorticoids at baseline and several neuroendocrine function tests convincingly indicate profound alterations of the HPA system in patients with severe depression [75]. Several investigations have shown baseline alterations in corticotropin and cortisol secretion in 20\%-50\% of depressed patients and characteristic modifications in specific HPA system function tests such as the combined dexamethasone-CRH challenge test. These findings are consistently suggestive of HPA system overactivity in up to $90 \%$ of all investigated patients with major depression [76]. Additionally, anxiety disorders have also been related to differences in cortisol responses [77]. On the 
other hand, during experimental pulmonary TB, there is overactivity of the HPA system, adrenal glands double their weight, and an increase of plasma corticosterone responds to ACTH stimulation [68] [78]. Thus, the over activation of the HPA axis in TB patients may produce depression and anxiety.

\subsubsection{Vasopressin}

The hypothalamic neuropeptide arginine vasopressin (VP) plays an essential role in the pathophysiology of affective disorders and the HPA axis's hyperactivity. After the first observation of HPA axis hyperactivity in depression, an increase in hypothalamic corticotrophin-releasing hormone (CRH) and hypothalamic AVP had been observed [79]. Postmortem studies and clinical research have described high VP levels in the brain and plasma of depressed patients. VP contributes to depressive and anxiety symptoms and shows anxiogenic and depressive actions [80]. Interestingly VP is abnormally high in plasma of some patients with pulmonary TB and is produced ectopically. Recently, in a BALB/c murine model of progressive pulmonary TB was showed that the VP gene is expressed mainly in macrophages from the lung since early infection, and progressively increased during disease progression. Moreover, chronic vasopressinergic stimulation during active late disease causes anti-inflammation and fibrosis, which is deleterious [71]. Additionally, circulating active neuropeptides like VP reach the brain parenchyma through the $\mathrm{BBB}$ in a minute [80], so it could be possible that the high levels of VP in the plasma of TB patients could be related to the anxiety and depression showed by these patients, if the ectopic production of VP reaches the brain.

\subsubsection{The Sympathetic Nervous System (SNS)}

The HPA axis and the SNS represent the principal pathways involved in the cross-talk between the brain and the immune system. The activation of the SNS in the context of an active immune system and stress results in the release of sympathetic neurotransmitters, especially norepinephrine (NE), which binds to $\beta$-adrenergic ( $\beta \mathrm{AR})$ and $\alpha$-adrenergic ( $\alpha \mathrm{AR})$ receptors expressed on peripheral immune cell populations [81]. The SNS has a central role in activating $\mathrm{T}$ cells and shifting the differentiation of haematopoietic stem cells in the bone marrow to proinflammatory monocytes, increasing the expression of proinflammatory molecules. Simultaneously, central microglial cells activate in response to neural signals as a result of stress circuit activation. These cells facilitate the infiltration of peripheral monocytes by secretion of specific cytokines and chemokines, modulating endothelial cell permeability, and allowing monocytes' ingress from the vascular lumen to the perivascular space and the brain parenchyma. The infiltrating proinflammatory monocytes lead to further sustained activation of neural stress circuits, resulting in abnormal behaviour. Besides, individuals who have developed psychopathology have elevated numbers of circulating proinflammatory monocytes and lymphocytes that amplified peripheral levels of cytokines and central microglial activation [63]. It has been shown that during early TB infection, adrenergic nerve terminals and lymphocytes located in pul- 
monary inflammatory infiltrates, and mediastinal lymph nodes produce high NE levels. These cells also overexpressed $\beta 2 \mathrm{AR}$ that promote Th- 1 cell differentiation favouring protection, while during late infection NE production and $\beta 2 \mathrm{AR}$ expression sharply decreased, suggesting that during advanced disease the SNS activity contributes to establishing local proinflammatory activity [70]. Thus, it could be possible that in TB patients that developed psychopathology, the SNS not only participates in the peripheral immune modulation, but also in the activation of neural stress circuits which could be related with the anxiety and depression symptoms.

\subsection{Brain Mechanisms}

Patients with chronic inflammatory diseases and major depression have reduced circulating tryptophan (TRP) levels and increased levels of kynurenine and other metabolites of the enzyme Indolamine-2,3-dioxygenase (IDO), which is a major tryptophan catabolising enzyme within the brain, kidney, lung, spleen, duodenum and immune cells. IDO is the rate-limiting enzyme in the TRP kynurenine pathway that converts TRP, the precursor of serotonin, to kynurenine, resulting in reduced central serotonin synthesis. Proinflammatory cytokines such as TNF $a$ and IFN $\gamma$ can up-regulate IDO expression activating the kynurenine pathway, decreasing central serotonin levels and contributing to anxiety and depressive symptoms. The kynurenine pathway metabolites are also neuroactive because kynurenine ratio to TRP is undoubtedly associated with depressive symptoms [82].

TB is a chronic infection with a rise in the synthesis of IFN $\gamma$, inducing IDO enzyme and leading TRP to the kynurenine pathway from the serotonin pathway [83]. The neurotoxic metabolites of the kynurenine pathway like 3-hydroxy-kynurenine and quinolinic acid generate free radicals that mediate neuronal damage and excitotoxicity, not only by stimulating N-Methyl-D-aspartate (NMDA) receptors but also directly causing the release of glutamate [84]. This might be associated with the development of anxiety depressive symptoms in TB patients. Moreover, this excessive excitotoxicity produced neuronal death provoking significant abnormalities in memory and cognitive functions.

\section{Clinical and Research Implications}

Since 1985, it has been proposed that individuals with TB need more effective public health interventions and psychiatric treatment [85]. People with TB and mental illness are at more significant risk of poor health-seeking behaviour and medication adherence with consequent adverse treatment outcomes including morbidity, mortality and ongoing disease transmission. Moreover, the potential for depression and anxiety to impair adherence to complex TB medication regimens is challenging in terms of individual patient outcomes and is a risk to public health by the potential for the development of multidrug resistance. Treating depression and anxiety and working with the patients to improve their disease perceptions will improve treatment adherence, disease outcomes and patient 
managing.

TB clinics must develop policies to screen and treat depression and anxiety among TB patients. Additional research on risk factors of depression and anxiety should be conducted to reinforce and broaden the current findings. Developing methods to address mental health issues associated with $\mathrm{TB}$ will lead to innovative methods of TB care and prevention. Furthermore, integrating TB and mental health services will go a long way in addressing the needs of susceptible populations and stopping the transmission of one of the most significant infectious disease. A better understanding of these issues can lead to TB programs' client-oriented comprehensive efforts to improve patients' quality of life.

Successful health programs address the disease's social and emotional impact and adopt support strategies to enhance acceptance. To design such a client-oriented comprehensive program for TB, we need to understand patients' perceptions regarding their physical, mental and social well-being.

\section{Conclusions}

$\mathrm{TB}$, anxiety and depression are diseases of high incidence in the population. These diseases are currently a significant public health problem. As we have seen, they have risk factors in common, and their relationship is syndemic, the presence of one favours the development of the other and the worsening of the disease. There is significant co-morbidity between TB and mental illness, and the treatment of patients with TB must be made integrally with the treatment of depression and anxiety. Anxiety and depression are factors that can influence the compliance and well-being of the patient.

Identifying risk factors and developing treatments to reduce these psychiatric diseases in patients with TB will allow us to control the disease better and stop its spread to other people and reduce multidrug resistance cases. Finally, more research is needed to comprehend the biological factors that could influence depression and anxiety in TB patients.

Evaluation and treatment of TB patients' mental disorders, which are significantly higher than the general population, may increase treatment compliance and reduce relapse. This can upgrade the prognosis and quality of life for patients with this chronic disease. Further prospective studies are needed to assess depression and anxiety in TB, especially concerning antitubercular therapy.

\section{Acknowledgements}

Jacqueline Viridiana Lara-Espinosa is affiliated to Programa de Doctorado en Ciencias Bioquimicas, Universidad Nacional Autónoma de México (UNAM) and receives fellowship from Consejo Nacional de Ciencia y Tecnología (CONACYT) (CVU 630838).

\section{Author Contributions}

J.V.L.-E. writing, review and editing, R.H.-P review and editing. Both authors 
have read and agreed to the published version of the manuscript.

\section{Conflicts of Interest}

The authors declare no conflicts of interest regarding the publication of this paper.

\section{References}

[1] Smith, I. (2003) Mycobacterium tuberculosis Pathogenesis and Molecular Determinants of Virulence. Clinical Microbiology Reviews, 16, 463-496.

https://doi.org/10.1128/CMR.16.3.463-496.2003

[2] Loddenkemper, R., Lipman, M. and Zumla, A. (2015) Clinical Aspects of Adult Tuberculosis. Cold Spring Harbor Perspectives in Medicine, 6, Article ID: a017848. https://doi.org/10.1101/cshperspect.a017848

[3] World Health Organization (2019) Global Tuberculosis Report 2019. CC BY-NCSA 3.0 IGO, World Health Organization, Geneva.

https://www.who.int/publications/i/item/global-tuberculosis-report-2019

[4] Gagneux, S. (2018) Ecology and Evolution of Mycobacterium tuberculosis. Nature Reviews Microbiology, 16, 202-213. https://doi.org/10.1038/nrmicro.2018.8

[5] Lund, C., Breen, A., Flisher, A.J., Kakuma, R., Corrigall, J., Joska, J.A., Swartz, L. and Patel, V. (2010) Poverty and Common Mental Disorders in Low and Middle Income Countries: A Systematic Review. Social Science \& Medicine, 71, 517-528. https://doi.org/10.1016/j.socscimed.2010.04.027

[6] GBD 2017 Disease and Injury Incidence and Prevalence Collaborators (2018) Global, Regional, and National Incidence, Prevalence, and Years Lived with Disability for 354 Diseases and Injuries for 195 Countries and Territories, 1990-2017: A Systematic Analysis for the Global Burden of Disease Study 2017. Lancet, 392, 1789-1858. https://doi.org/10.1016/S0140-6736(18)32279-7

[7] Marcus, M., Yasamy, M.T., van Ommeren, M. and Chisholm, D. (2012) Depression, a Global Public Health Concern. World Health Organization Department of Mental Health and Substance Abuse, Geneva, 1-8.

[8] Husain, M.O., Dearman, S.P., Chaudhry, I.B., Rizvi, N. and Waheed, W. (2008) The Relationship between Anxiety, Depression and Illness Perception in Tberculosis Patients in Pakistan. Clinical Practice and Epidemiology in Mental Health, 4, Article No. 4. https://doi.org/10.1186/1745-0179-4-4

[9] Boing, A.F., Melo, G.R., Boing, A.C., Moretti-Pires, R.O., Peres, K.G. and Peres, M.A. (2012) Association between Depression and Chronic Diseases: Results from a Population-Based Study. Revista de Saúde Pública, 46, 617-623. https://doi.org/10.1590/S0034-89102012005000044

[10] Bystritsky, A., Khalsa, S.S., Cameron, M.E. and Schiffman, J. (2013) Current Diagnosis and Treatment of Anxiety Disorders. P\&T: A Peer-Reviewed Journal for Formulary Management, 38, 30-57.

https://www.ncbi.nlm.nih.gov/pmc/articles/PMC3628173/pdf/ptj3801030.pdf

[11] Wang, X.B., Li, X.L., Zhang, Q., Zhang, J., Chen, H.Y., Xu, W.Y., Fu, Y.H., Wang, Q.Y., Kang, J. and Hou, G. (2018) A Survey of Anxiety and Depressive Symptoms in Pulmonary Tuberculosis Patients with and without Tracheobronchial Tuberculosis. Frontiers in Psychiatry, 9, 308. https://doi.org/10.3389/fpsyt.2018.00308

[12] Rajeswari, R., Muniyandi, M., Balasubramanian, R. and Narayanan, P.R. (2005) Perceptions of Tuberculosis Patients about Their Physical, Mental and Social 
Well-Being: A Field Report from South India. Social Science \& Medicine, 60, 1845-1853. https://doi.org/10.1016/j.socscimed.2004.08.024

[13] Wells, K.B., Golding, J.M. and Burnam, M.A. (1988) Psychiatric Disorder in a Sample of the General Population with and without Chronic Medical Conditions. American Journal of Psychiatry, 145, 976-981. https://doi.org/10.1176/ajp.145.8.976

[14] van den Heuvel, L., Chishinga, N., Kinyanda, E., Weiss, H., Patel, V., Ayles, H., Harvey, J., Cloete, K.J. and Seedat, S. (2013) Frequency and Correlates of Anxiety and Mood Disorders among TB- and HIV-Infected Zambians. AIDS Care, 25, 1527-1535. https://doi.org/10.1080/09540121.2013.793263

[15] Yen, Y.F., Chung, M.S., Hu, H.Y., Lai, Y.J., Huang, L.Y., Lin, Y.S., Chou, P. and Deng, C.Y. (2015) Association of Pulmonary Tuberculosis and Ethambutol with Incident Depressive Disorder: A Nationwide, Population-Based Cohort Study. The Journal of Clinical Psychiatry, 76, e505-e511.

[16] Javaid, A., Mehreen, S., Khan, M.A., Ashiq, N. and Ihtesham, M. (2017) Depression and Its Associated Factors with Multidrug-Resistant Tuberculosis at Baseline. Journal of Depression and Anxiety, 6, 1-6. https://doi.org/10.4172/2167-1044.1000253

[17] Mathai, P.J., Ravindran, P., Joshi, P. and Sundaram, P. (1981) Psychiatric Morbidity in Pulmonary Tuberculosis-A Clinical Study. Indian Journal of Psychiatry, 23, 66-68.

https://www.ncbi.nlm.nih.gov/pmc/articles/PMC3013189/pdf/IJPsy-23-66.pdf

[18] Shyamala, K.K., Naveen, R.S. and Khatri, B. (2018) Depression: A Neglected Co-Morbidity in Patients with Tuberculosis. The Journal of the Association of Physicians of India, 66, 18-21.

[19] Singh, L., Pardal, P.K. and Prakash, J (2015). Psychiatric Morbidity in Patients of Pulmonary Tuberculosis-An Observational Study. Industrial Psychiatry Journal, 24, 168-171. https://doi.org/10.4103/0972-6748.181722

[20] Kruijshaar, M.E., Lipman, M., Essink-Bot, M.L., Lozewicz, S., Creer, D., Dart, S., Maguire, H. and Abubakar, I. (2010) Health Status of UK Patients with Active Tuberculosis. The International Journal of Tuberculosis and Lung Disease, 14, 296-302.

https://www.ingentaconnect.com/content/iuatld/ijtld/2010/00000014/00000003/art0 $\underline{0012}$

[21] Rubeen, R., Zareen, N., Zameer, S., Rasool, A.G., Naqvi, S.S.N. and Iqbal, J. (2014) Anxiety and Depression in Tuberculosis Can Create Impact on Quality of Life of Patient. Acta Medica International, 1, 93-98.

[22] Kumar, K., Kumar, A., Chandra, P. and Kansal, H.M. (2016) A Study of Prevalence of Depression and Anxiety in Patients Suffering from Tuberculosis. Journal of Family Medicine and Primary Care, 5, 150-153. https://doi.org/10.4103/2249-4863.184641

[23] Aghanwa, H.S. and Erhabor, G.E. (1998) Demographic/Socioeconomic Factors in Mental Disorders Associated with Tuberculosis in Southwest Nigeria. Journal of Psychosomatic Research, 45, 353-360. https://doi.org/10.1016/S0022-3999(98)00006-3

[24] Vega, P., Sweetland, A., Acha, J., Castillo, H., Guerra, D., Smith Fawzi, M.C. and Shin, S. (2004) Psychiatric Issues in the Management of Patients with Multidrug-Resistant Tuberculosis. The International Journal of Tuberculosis and Lung Disease, 8, 749-759.

https://www.ingentaconnect.com/content/iuatld/ijtld/2004/00000008/00000006/art0 
$\underline{0011}$

[25] Walker, I.F., Kanal, S., Baral, S.C., Farragher, T.M., Joshi, D., Elsey, H. and Newell, J.N. (2019) Depression and Anxiety in Patients with Multidrug-Resistant Tuberculosis in Nepal: An Observational Study. Public Health Action, 9, 42-48. https://doi.org/10.5588/pha.18.0047

[26] Aydin, I.O. and Uluşahin, A. (2001) Depression, Anxiety Co-Morbidity, and Disability in Tuberculosis and Chronic Obstructive Pulmonary Disease Patients: Applicability of GHQ-12. General Hospital Psychiatry, 23, 77-83. https://doi.org/10.1016/S0163-8343(01)00116-5

[27] Issa, B.A., Yussuf, A.D. and Kuranga, S.I. (2009) Depression Co-Morbidity among Patients with Tuberculosis in a University Teaching Hospital Outpatient Clinic in Nigeria. Mental Health in Family Medicine, 6, 133-138. https://www.ncbi.nlm.nih.gov/pmc/articles/PMC2838651/pdf/MHFM-06-133.pdf

[28] Aamir, S. and Aisha. (2010) Co-Morbid Anxiety and Depression among Pulmonary Tuberculosis Patients. Journal of the College of Physicians and Surgeons-Pakistan, 20, 703-704.

[29] Sulehri, M.A., Dogar, I.A., Sohail, H., Mehdi, Z., Azam, M., Niaz, O., Sheraz, M., Sajjad, I.A. and Iqbal, Z. (2010) Prevalence of Depression among Tuberculosis Patients. Annals of Punjab Medical College, 4, 133-137. http://apmcfmu.com/index.php/apmc/article/view/546/464

[30] Ige, O.M. and Lasebikan, V.O. (2011) Prevalence of Depression in Tuberculosis Patients in Comparison with Non-Tuberculosis Family Contacts Visiting the DOTS Clinic in a Nigerian Tertiary Care Hospital and Its Correlation with Disease Pattern. Mental Health in Family Medicine, 8, 235-241. https://www.ncbi.nlm.nih.gov/pmc/articles/PMC3487604/pdf/MHFM-08-235.pdf

[31] Adina, M.M., Necrelescu, O.L., Bondor, C., Trofor, A., Alexandrescu, D., Dantes, E., et al. (2011) Depressive Syndrome, Anxiety and Illness Perception in Tuberculosis Patients. Recent Researches in Modern Medicine, 978, 243-248.

https://www.researchgate.net/profile/Elena_Dantes2/publication/265498301_Depre ssive_syndrome_anxiety_and_illness_perception_in_Tuberculosis_patients/links/55 183d310cf2d70ee27b2cb6.pdf

[32] Peltzer, K. and Louw, J. (2013) Prevalence of Suicidal Behaviour \& Associated Factors among Tuberculosis Patients in Public Primary Care in South Africa. The Indian Journal of Medical Research, 138, 194-200. https://www.ncbi.nlm.nih.gov/pmc/articles/PMC3788204/

[33] Ugarte-Gil, C., Ruiz, P., Zamudio, C., Canaza, L., Otero, L., Kruger, H. and Seas, C. (2013) Association of Major Depressive Episode with Negative Outcomes of Tuberculosis Treatment. PLOS ONE, 8, e69514.

https://doi.org/10.1371/journal.pone.0069514

[34] Atif, M., Sulaiman, S.A., Shafie, A.A., Asif, M., Sarfraz, M.K., Low, H.C. and Babar, Z.U. (2014) Impact of Tuberculosis Treatment on Health-Related Quality of Life of Pulmonary Tuberculosis Patients: A Follow-Up Study. Health and Quality of Life Outcomes, 12, Article No. 19. https://doi.org/10.1186/1477-7525-12-19

[35] Masumoto, S., Yamamoto, T., Ohkado, A., Yoshimatsu, S., Querri, A.G. and Kamiya, Y. (2014) Prevalence and Associated Factors of Depressive State among Pulmonary Tuberculosis Patients in Manila, The Philippines. The International Journal of Tuberculosis and Lung Disease, 18, 174-179. https://doi.org/10.5588/ijtld.13.0335

[36] Kibrisli, E., Bez, Y., Yilmaz, A., Aslanhan, H., Taylan, M., Kaya, H., Tanrikulu, A.C. 
and Abakay, O. (2015) High Social Anxiety and Poor Quality of Life in Patients with Pulmonary Tuberculosis. Medicine, 94, e413. https://doi.org/10.1097/MD.0000000000000413

[37] Duko, B., Gebeyehu, A. and Ayano, G. (2015) Prevalence and Correlates of Depression and Anxiety among Patients with Tuberculosis at WolaitaSodo University Hospital and Sodo Health Center, WolaitaSodo, South Ethiopia, Cross Sectional Study. BMC psychiatry, 15, Article No. 214.

https://doi.org/10.1186/s12888-015-0598-3

[38] Emami, H., Modarressi, T., Najmi, K., Radmand, G., Monjazebi, F., Tabarsi, P. and Richter, J. (2015) Psychological Symptoms before and after a 14-Day Initial Inpatient Treatment in Tuberculosis Patients Compared with Their Primary Caregivers and Healthy Controls. Tanaffos, 14, 182-192.

https://www.ncbi.nlm.nih.gov/pmc/articles/PMC4745187/pdf/Tanaffos-14-182.pdf

[39] Galhenage, J.S., Rupasinghe, J.P., Abeywardena, G.S., de Silva, A.P., Williams, S.S. and Gunasena, B. (2016) Psychological Morbidity and Illness Perception among Patients Receiving Treatment for Tuberculosis in a Tertiary Care Centre in Sri Lanka. The Ceylon Medical Journal, 61, 37-40. https://doi.org/10.4038/cmj.v61i1.8261

[40] Chen, X., Zhao, Y., Xu, Y., Zhang, H.W., Sun, S.H., Gao, Z.D. and He, X.X. (2016) Analysing the Status of Depression and Anxiety of New Registered Tuberculosis Outpatients and Correlations with Social Support Influence Factors. National Medical Journal of China, 96, 2749-2753.

[41] Yilmaz, A. and Dedeli, O. (2016) Assessment of Anxiety, Depression, Loneliness and Stigmatisation in Patients with Tuberculosis. Acta Paulista de Enfermagem, 29, 549-557. https://doi.org/10.1590/1982-0194201600076

[42] Amreen and Rizvi N. (2016) Frequency of Depression and Anxiety among Tuberculosis Patients. Journal of Tuberculosis Research, 4, 183-190.

https://doi.org/10.4236/jtr.2016.44021

[43] Kehbila, J., Ekabe, C.J., Aminde, L.N., Noubiap, J.J., Fon, P.N. and Monekosso, G.L. (2016) Prevalence and Correlates of Depressive Symptoms in Adult Patients with Pulmonary Tuberculosis in the Southwest Region of Cameroon. Infectious Diseases of Poverty, 5, Article No. 51. https://doi.org/10.1186/s40249-016-0145-6

[44] Paulo, B.X. and Peixoto, B. (2016) Emotional Distress Patients with Several Types of Tuberculosis. A Pilot Study with Patients from the Sanatorium Hospital of Huambo. International Journal of Mycobacteriology, 5, S58. https://doi.org/10.1016/j.ijmyco.2016.11.002

[45] Dos Santos, A.P., Lazzari, T.K. and Silva, D.R. (2017) Health-Related Quality of Life, Depression and Anxiety in Hospitalised Patients with Tuberculosis. Tuberculosis and Respiratory Diseases, 80, 69-76. https://doi.org/10.4046/trd.2017.80.1.69

[46] Gong, Y., Yan, S., Qiu, L., Zhang, S., Lu, Z., Tong, Y., Fang, P. and Yin, X. (2018) Prevalence of Depressive Symptoms and Related Risk Factors among Patients with Tuberculosis in China: A Multistage Cross-Sectional Study. The American Journal of Tropical Medicine and Hygiene, 98, 1624-1628.

https://doi.org/10.4269/ajtmh.17-0840

[47] Qiu, L., Yang, Q., Tong, Y., Lu, Z., Gong, Y. and Yin, X. (2018). The Mediating Effects of Stigma on Depressive Symptoms in Patients with Tuberculosis: A Structural Equation Modeling Approach. Frontiers in Psychiatry, 9, 618. https://doi.org/10.3389/fpsyt.2018.00618

[48] Walker, I.F., Khan, A.M., Khan, A.M., Khan, N.M., Ayub, R.M., Ghias, K.N. and Walley, J.D. (2018) Depression among Multidrug-Resistant Tuberculosis Patients in 
Punjab, Pakistan: A Large Cross-Sectional Study. The International Journal of Tuberculosis and Lung Disease, 22, 773-778. https://doi.org/10.5588/ijtld.17.0788

[49] Salodia, U.P., Sethi, S. and Khokhar, A. (2019) Depression among Tuberculosis Patients Attending a DOTS Centre in a Rural Area of Delhi: A Cross-Sectional Study. Indian Journal of Public Health, 63, 39-43.

https://doi.org/10.4103/ijph.IJPH_109_18

[50] Castro-Silva, K.M., Carvalho, A.C., Cavalcanti, M.T., Martins, P., França, J.R., Oquendo, M., Kritski, A.L. and Sweetland, A. (2019) Prevalence of Depression among Patients with Presumptive Pulmonary Tuberculosis in Rio de Janeiro, Brazil. Brazilian Journal of Psychiatry, 41, 316-323.

https://doi.org/10.1590/1516-4446-2018-0076

[51] Dasa, T.T., Roba, A.A., Weldegebreal, F., Mesfin, F., Asfaw, A., Mitiku, H., Teklemariam, Z., Geddugol, B.J., Naganuri, M., Befikadu, H. and Tesfaye, E. (2019) Prevalence and Associated Factors of Depression among Tuberculosis Patients in Eastern Ethiopia. BMC Psychiatry, 19, Article No. 82. https://doi.org/10.1186/s12888-019-2042-6

[52] Ambaw, F., Mayston, R., Hanlon, C. and Alem, A. (2020) Incidence of Depression in People with Newly Diagnosed Tuberculosis in Ethiopia: A Cohort Study. Global Mental Health, 7, e1. https://doi.org/10.1017/gmh.2019.27

[53] Mohammedhussein, M., Alenko, A., Tessema, W. and Mamaru, A. (2020) Prevalence and Associated Factors of Depression and Anxiety among Patients with Pulmonary Tuberculosis Attending Treatment at Public Health Facilities in Southwest Ethiopia. Neuropsychiatric Disease and Treatment, 16, 1095-1104. https://doi.org/10.2147/NDT.S249431

[54] Nyasulu, P., Sikwese, S., Chirwa, T., Makanjee, C., Mmanga, M., Babalola, J.O., Mpunga, J., Banda, H.T., Muula, A.S. and Munthali, A.C. (2018) Knowledge, Beliefs, and Perceptions of Tuberculosis among Community Members in Ntcheu District, Malawi. Journal of Multidisciplinary Healthcare, 11, 375-389. https://doi.org/10.2147/JMDH.S156949

[55] Wondawek, T.M. and Ali, M.M. (2019) Delay in Treatment Seeking and Associated Factors among Suspected Pulmonary Tuberculosis Patients in Public Health Facilities of Adama Town, Eastern Ethiopia. BMC Public Health, 19, Article No. 1527. https://doi.org/10.1186/s12889-019-7886-7

[56] Moya, E. and Lusk, M. (2013) Tuberculosis Stigma and Perceptions in the US-Mexico Border. Salud pública de México, 55, S498-S507.

https://doi.org/10.21149/spm.v55s4.5155

https://www.scielosp.org/article/spm/2013.v55suppl4/s498-s507/

[57] Craig, G.M., Daftary, A., Engel, N., O’Driscoll, S. and Ioannaki, A. (2017) Tuberculosis Stigma as a Social Determinant of Health: A Systematic Mapping Review of Research in Low Incidence Countries. International Journal of Infectious Diseases, 56, 90-100. https://doi.org/10.1016/j.ijid.2016.10.011

[58] Courtwright, A. and Turner, A.N. (2010) Tuberculosis and Stigmatization: Pathways and Interventions. Public Health Reports, 125, 34-42.

https://doi.org/10.1177/00333549101250S407

[59] Mak, W.W., Poon, C.Y., Pun, L.Y. and Cheung, S.F. (2007) Meta-Analysis of Stigma and Mental Health. Social Science \& Medicine, 65, 245-261.

https://doi.org/10.1016/j.socscimed.2007.03.015

[60] Hansel, N.N., Wu, A.W., Chang, B. and Diette, G.B. (2004) Quality of Life in Tuberculosis: Patient and Provider Perspectives. Quality of Life Research, 13, 639-652. 
https://doi.org/10.1023/B:QURE.0000021317.12945.f0

[61] Morris, M.D., Quezada, L., Bhat, P., Moser, K., Smith, J., Perez, H., Laniado-Laborin, R., Estrada-Guzman, J. and Rodwell, T.C. (2013) Social, Economic, and Psychological Impacts of MDR-TB Treatment in Tijuana, Mexico: a Patient's Perspective. The International Journal of Tuberculosis and Lung Disease, 17, 954-960. https://doi.org/10.5588/ijtld.12.0480

[62] Doherty, A.M., Kelly, J., McDonald, C., O’Dywer, A.M., Keane, J. and Cooney, J. (2013) A Review of the Interplay between Tuberculosis and Mental Health. General Hospital Psychiatry, 35, 398-406. https://doi.org/10.1016/j.genhosppsych.2013.03.018

[63] Mondelli, V. and Vernon, A.C. (2019) From Early Adversities to Immune Activation in Psychiatric Disorders: The Role of the Sympathetic Nervous System. Clinical and Experimental Immunology, 197, 319-328. https://doi.org/10.1111/cei.13351

[64] Chandra, M., Rana, P., Chandra, K. and Arora, V.K. (2019) Tuberculosis-Depression Syndemic: A Public Health Challenge. The Indian Journal of Tuberculosis, 66, 197-202. https://doi.org/10.1016/j.ijtb.2019.02.007

[65] Hernández, M.E., Becerril, L., Alvarez, L. and Pavón-Romero, L. (2007) Vías de neuroinmunomodulación. Primera parte. Salud Mental, 30, 13-19.

https://www.medigraphic.com/pdfs/salmen/sam-2007/sam076b.pdf

[66] Ferraz, J.C., Melo, F.B., Albuquerque, M.F., Montenegro, S.M. and Abath, F.G. (2006) Immune Factors and Immunoregulation in Tuberculosis. Brazilian Journal of Medical and Biological Research, 39, 1387-1397. https://doi.org/10.1590/S0100-879X2006001100002

[67] Lara-Espinosa, J.V., Santana-Martínez, R.A., Maldonado, P.D., Zetter, M., BecerrilVillanueva, E., Pérez-Sánchez, G., Pavón, L., Mata-Espinosa, D., Barrios-Payán, J., López-Torres, M.O., Marquina-Castillo, B. and Hernández-Pando, R. (2020) Experimental Pulmonary Tuberculosis in the Absence of Detectable Brain Infection Induces Neuroinflammation and Behavioural Abnormalities in Male BALB/c Mice. International Journal of Molecular Sciences, 21, 9483. https://doi.org/10.3390/ijms21249483

[68] Hernandez-Pando, R., Orozco, H., Honour, J., Silva, P., Leyva, R. and Rook, G.A. (1995) Adrenal Changes in Murine Pulmonary Tuberculosis; a Clue to Pathogenesis? FEMS Immunology and Medical Microbiology, 12, 63-72. https://doi.org/10.1111/j.1574-695X.1995.tb00176.x

[69] Rey, A.D., Mahuad, C.V., Bozza, V.V., Bogue, C., Farroni, M.A., Bay, M.L., Bottasso, O.A. and Besedovsky, H.O. (2007) Endocrine and Cytokine Responses in $\mathrm{Hu}$ mans with Pulmonary Tuberculosis. Brain, Behavior, and Immunity, 21, 171-179. https://doi.org/10.1016/j.bbi.2006.06.005

[70] Barrios-Payán, J., Revuelta, A., Mata-Espinosa, D., Marquina-Castillo, B., Villanueva, E.B., Gutiérrez, M.E., Pérez-Sánchez, G., Pavón, L. and Hernandez-Pando, R. (2016) The Contribution of the Sympathetic Nervous System to the Immunopathology of Experimental Pulmonary Tuberculosis. Journal of Neuroimmunology, 298, 98-105. https://doi.org/10.1016/j.jneuroim.2016.07.012

[71] Zetter, M., Barrios-Payán, J., Mata-Espinosa, D., Marquina-Castillo, B., Quintanar-Stephano, A. and Hernández-Pando, R. (2019) Involvement of Vasopressin in the Pathogenesis of Pulmonary Tuberculosis: A New Therapeutic Target? Frontiers in Endocrinology, 10, 351. https://doi.org/10.3389/fendo.2019.00351

[72] McEwen, B.S. (1998) Stress, Adaptation, and Disease: Allostasis and Allostatic Load. Annals of the New York Academy of Sciences, 840, 33-44. 
https://doi.org/10.1111/j.1749-6632.1998.tb09546.x

[73] Sapolsky, R.M., Romero, L.M. and Munck, A.U. (2000) How Do Glucocorticoids Influence Stress Responses? Integrating Permissive, Suppressive, Stimulatory, and Preparative Actions. Endocrine Reviews, 21, 55-89.

https://doi.org/10.1210/er.21.1.55

[74] McEwen, B.S. and Gianaros, P.J. (2010) Central Role of the Brain in Stress and Adaptation: Links to Socioeconomic Status, Health, and Disease. Annals of the New York Academy of Sciences, 1186, 190-222. https://doi.org/10.1111/j.1749-6632.2009.05331.x

[75] Barden, N. (2004) Implication of the Hypothalamic-Pituitary-Adrenal Axis in the Physiopathology of Depression. Journal of Psychiatry \& Neuroscience, 29, 185-193.

[76] Heuser, I., Yassouridis, A. and Holsboer, F. (1994) The Combined Dexamethasone/CRH Test: A Refined Laboratory Test for Psychiatric Disorders. Journal of Psychiatric Research, 28, 341-356. https://doi.org/10.1016/0022-3956(94)90017-5

[77] Elnazer, H.Y. and Baldwin, D.S. (2014) Investigation of Cortisol Levels in Patients with Anxiety Disorders: A Structured Review. In: Pariante, C. and Lapiz-Bluhm, M., Eds., Behavioral Neurobiology of Stress-Related Disorders, Vol. 18, Springer, Berlin, Heidelberg, 191-216. https://doi.org/10.1007/7854_2014_299

[78] Rook, G.A. (2007) Endocrine and Cytokine Responses in Humans with Pulmonary Tuberculosis. Brain, Behavior, and Immunity, 21, 169-170.

https://doi.org/10.1016/j.bbi.2006.08.003

[79] Müller, M. B., Landgraf, R. and Keck, M.E. (2000) Vasopressin, Major Depression, and Hypothalamic-Pituitary-Adrenocortical Desensitisation. Biological Psychiatry, 48, 330-333. https://doi.org/10.1016/S0006-3223(00)00886-6

[80] Neumann, I.D. and Landgraf, R. (2012) Balance of Brain Oxytocin and Vasopressin: Implications for Anxiety, Depression, and Social Behaviors. Trends in Neuros ciences, 35, 649-659. https://doi.org/10.1016/j.tins.2012.08.004

[81] Elenkov, I.J., Wilder, R.L., Chrousos, G.P. and Vizi, E.S. (2000) The Sympathetic nerve-An Integrative Interface between Two Supersystems: The Brain and the Immune System. Pharmacological Reviews, 52, 595-638.

[82] Maes, M., Verkerk, R., Bonaccorso, S., Ombelet, W., Bosmans, E. and Scharpé, S. (2002) Depressive and Anxiety Symptoms in the Early Puerperium Are Related to Increased Degradation of Tryptophan into Kynurenine, a Phenomenon Which Is Related to Immune Activation. Life Sciences, 71, 1837-1848.

https://doi.org/10.1016/S0024-3205(02)01853-2

[83] Dantzer, R., O’Connor, J.C., Freund, G.G., Johnson, R.W. and Kelley, K.W. (2008) From Inflammation to Sickness and Depression: When the Immune System Subjugates the Brain. Nature Reviews Neuroscience, 9, 46-56. https://doi.org/10.1038/nrn2297

[84] Rana, P., Sharma, A.K., Jain, S., Deshmukh, P., Bhattacharya, S.K., Banerjee, B.D. and Mediratta, P.K. (2016) Comparison of Fluoxetine and 1-methyl-L-tryptophan in Treatment of Depression-Like Illness in Bacillus Calmette-Guerin-Induced Inflammatory Model of Depression in Mice. Journal of Basic and Clinical Physiology and Pharmacology, 27, 569-576. https://doi.org/10.1515/jbcpp-2015-0120

[85] Moran, M.G. (1985) Psychiatric Aspects of Tuberculosis. Advances in Psychosomatic Medicine, 14, 109-118. https://doi.org/10.1159/000411840 